\title{
Low Vitamin D Serum Levels May Be a Modifiable Risk Factor for Obesity and Cognitive Impairment in Middle-Age Egyptian Women
}

\author{
Yusr I. Kazem, Maha I. A. Moaty*, Salwa M. El-Shebini, Salwa T. Tapozada, Laila M. Hanna \\ National Research Center, Nutrition and Food Science Department, Cairo, Egypt
}

\begin{abstract}
Citation: Kazem YI, Moaty MIA, El-Shebini SM Tapozada ST, Hanna LM. Low Vitamin D Serum Levels May Be a Modifiable Risk Factor for Obesity and Cognitive Impairment in Middle-Age Egyptian Women. OA Maced J Med Sci. 2014 Egyptian Women. OA Maced J Med Sci. 2014 hun 15 ; 1 2(2):283-28 Key words: Vitamin D; Obesity; cognitive functions; females; insulin resistance.

Correspondence: Dr. Maha Abdel-Moaty. NationalReserarch Center, Dokki, Cairo 12311, Egypt. E-Mail: ibrahim.maha@yahoo.com

Received: 12-Apr-2014; Revised: 12-May2014; Accepted: 14-Amay-2014; Online first: 10-Jun-2014

Copyright: () 2014 Kazem et al. This is an open access article distributed under the terms of the Creative Commons Attribution License, which permits unrestricted use, distribution, and reproduction in any medium, provided the original author and source are credited.

Competing Interests: The authors have declared that no competing interests exist.
\end{abstract}

\begin{abstract}
OBJECTIVE: To evaluate the levels of serum vitamin D (25-hydroxyvitamin D) among obese Egyptian females and search possible association with cognitive functions and insulin resistance.

SUBJECTS AND METHODS: This study included 2 groups, Group-1(cases) consists of 120 obese females and Group-2 (controls) consists of 30 non-obese females. The included females were subjected to full clinical examination, anthropometric measurements and Kendrick Battery for evaluation of cognitive functions (short term memory and attention). Evaluation of serum Vitamin D, Parathyroid hormone, C-peptide and fasting blood glucose were done. The obese group was put on a balanced low caloric diet (900-1000 K Calories/day) for 2 months, where reevaluation was performed.

RESULTS: Comparing obese group with non-obese control group revealed significant lower mean level of serum vitamin $D$ associated with significant lower cognitive functions test and higher fasting blood glucose. After 2 months of low caloric diet, a significant increase in the serum level of vitamin $D$, accompanied with improvement in cognitive functions and decrease in fasting blood glucose and improved insulin resistance was seen. A correlation is found between vitamin D serum level and cognitive functions.
\end{abstract}

CONCLUSION: A lower vitamin D serum level could be a modifiable risk factor for obesity, insulin resistance and cognitive impairment in middle age females.

\section{Introduction}

Several studies suggested that lower vitamin $\begin{array}{lll}\text { D (25-hydroxyvitamin } & \text { D) concentrations are }\end{array}$ associated with poorer cognitive function and a higher risk of Alzheimer's disease (AD) [1, 2]. Low vitamin $D$ (VD) concentrations are prevalent worldwide for all age groups [3,4]. The VD insufficiency may be a modifiable risk factor for dementia as the role of VD in brain function is becoming clearer. Vitamin D receptors are located in the human cortex and hippocampus, which are key areas for cognition. At the molecular level, the brain has the ability to synthesize the active form of VD $(1,25$ dihydroxyvitamin D) within many cell types and regions with predominance in the hypothalamus and the large neurons within the substantia nigra. Functionally, VD contributes to neuroprotection by modulating the production of nerve growth factor [5].

A systematic review summarized studies that contained measurements of VD and related these to measures of cognition or dementia [6]. The meta- analyses showed Mini Mental State Examination (MMSE) scores were lower in individuals with lower VD concentrations, and that individuals with $A D$ had lower VD concentrations compared to those without AD. The studies included various populations, study numbers, study designs, cognitive tests, confounders, statistical tests, VD methods, and groupings [7, 8].

As with obesity, VD deficiency is reaching epidemic proportions worldwide, in both pediatric as well as adult populations [9]. Evidence is accumulating to suggest that there is a potential link between obesity and VD deficiency among global populations [10]. Several studies reported low serum level of VD in obese individuals [11]. Beyond VD's historic role in bone mineralization to its more recent association with allergy development reports to date have linked VD deficiency to hypertension, diabetes mellitus and insulin resistance (IR), non-alcoholic fatty liver disease (NAFLD) and cognitive impairment [12].

Several studies suggested that glucose metabolism and body fat content depend on serum VD levels. Consequently, VD deficiency may no 
longer be a condition, but rather a mediator of metabolic diseases responsible for the long-term health outcomes of obese population [13]. A study showed that low VD levels are associated with increased plasma glucose levels and decreased insulin sensitivity index [14]. A lower VD level could be a risk factor for developing insulin resistance and type 2 diabetes in obese population [15]. Excess body fat is associated with an increased risk of suboptimal VD status, it is unclear as to whether poor VD status is a consequence of obesity or is actively involved in its development. Until now, data regarding the role of VD are inconclusive [16]. The link between cognitive impairment and obesity has been reported in previous studies mediated through insulin resistance $[17,18]$. The VD deficiency may be an additional mode of action that contributes to the cognitive impairment reported in the obese individuals.

The primary objective of this study is to evaluate levels of serum VD [25(OH) D] among obese Egyptian females and search for possible association with cognitive functions, serum blood glucose and insulin resistance.

\section{Subjects and Methods}

\section{Subjects}

This study included 2 groups; Group 1 (cases) consists of 120 obese female, mean BMI (38.4 \pm 6.9$)$, and Group 2 (controls) consists of 30 non-obese females, mean BMI $(24.1 \pm 1.2)$, mean age for both groups (47.8 \pm 6.4 years). Both groups were of matching social, educational, medical and environmental background. They were all working females and belonged to middle social class. All cases were enrolled in a program for losing weight at the Nutrition Department at the National research center. The protocol of the study was approved by the National Research Center Ethics Committee. In addition an informed consent was obtained from each participant to be included in the study.

Inclusion criteria were that: they were not suffering from any mental, neurological or critical health problems, and not receiving drugs or nutritional supplements that affect cognitive functions or evaluated biochemical variables

\section{Methods}

\section{All included cases were subjected to:}

1 - Full clinical examination and assessment of blood pressure.

2 - Evaluation of cognitive functions and detection of dementia. Kendrick Battery for the Detection of Dementia was used for assessing memory status and attention [19]. The battery consists of two tests: a - The Object Learning Test (OLT): a test of recall of everyday objects after viewing for a brief period (assessment of memory and recalling). The OLT consists of four cards and has two forms, A and $\mathrm{B}$ for test-retest. It has a possible maximum score of 70 . Dementia is diagnosed if the individual got a score less than 26 points, and in this case she is excluded from the study. A higher OLT score indicates better memory status. b - The Digit Copying Test (DCT): a simple test of speed- performance (to assess attention and focus). It consists of a 10 by 10 matrix of the digits 0-9 each occurring randomly ten times within the matrix, the upper limit of the DCT is not defined. Dementia is detected if the volunteer needed 2 minutes or more to finish copying the digits. The given scores are the number of seconds needed to finish copying the matrix. The less time taken the better is the level of attention and vice-versa, the score is inversely related to the attention status. Both tests are timed.

3 - The anthropometric examination: Measurements of height and body weight were taken according to standard method. Body mass index $(\mathrm{BMI})=$ weight in $\mathrm{kg} / \mathrm{square}$ height in meters was calculated.

4 - Blood sampling and Biochemical analysis: Blood samples were drawn in the morning from all subjects after twelve hours fasting. The blood samples were allowed to clot, centrifuged and sera separated. Fasting blood glucose (FBG) was determined in fresh sera using the oxide peroxidase method [20]. The remaining sera were divided into aliquots and stored in eppindorf tubes at $-70{ }^{\circ} \mathrm{C}$ until used for further analysis. - Serum C-peptide was determined by Immunospec Corporation ELISA Kit 9428 Eton Ave,Unit 0 chats worth CA 91311 catalog No E1- 071 [21]. - According to $\mathrm{Li}$ et al. (2004) [22], insulin resistance was expressed by modified homeostasis model assessment-insulin resistance (M.HOMA-IR) $=1.5+$ FBG $(\mathrm{mg} / \mathrm{dl}) \times$ fasting C-peptide $(\mathrm{ng} / \mathrm{ml}) / 2800$, in which insulin was replaced by $\mathrm{C}$-peptide so as to be applied on diabetic patients using exogenous insulin. Serum 25 hydroxy vitamin D $(25(\mathrm{OH}) \quad \mathrm{D})$ was assessed by Vitamin D direct ELISA kit (EIA-4696) DRG ® International, Inc. USA [23]. - Serum parathyroid hormone (PTH) was measured by human PTH ELISA kit (hPTH-EASIA) KAP1481 DIAsource ImmunoAssays S.A. - Rue de l'Industrie, 8 - B-1400 Nivelle - Belgium [24]. The obese group was put on a balanced low caloric (900-1000 K calories/ day) diet for 2 months, A clear detailed sheet for the diet regimen was given at the first visit to each patient, weekly follow up was performed to assure exact and correct adherence to the diet, no VD supplementation was given.

\section{Study design and Statistics}

This is a comparative case-control study between obese cases and normal BMI control. Also to 
compare data before and after 2 month of balanced low caloric diet among the obese group $t$-student tests were used. Correlations of data at the base line were also performed. Statistical analysis was performed using SPSS (10) software. Data is expressed as means \pm SD. Pearson's correlation coefficient $(r)$ was calculated to find correlations between different variables. $P$ value considered significant at $<0.05$.

\section{Results}

Table 1 shows a significant $(P=0.000)$ lower vitamin $D$ serum levels among the obese group (47.6 $\pm 7.7 \mathrm{nmol} / \mathrm{L})$ compared to the normal non obese group $(68.3 \pm 9.3 \mathrm{nmol} / \mathrm{L})$ which is still below the adequate level ( $\geq 75 \mathrm{nmol} / \mathrm{L})$. Also a significant difference is seen in cognitive functions test results; both the short memory and attention, where the control non obese group showed statistically significant better results $(P=0.000)$. In addition, the mean fasting blood glucose (FBG) $(119.5 \pm 40 \mathrm{mg} / \mathrm{dl})$ is significantly higher than the control group (82.1 \pm $6.7 \mathrm{mg} / \mathrm{dl})(P=0.000)$.

Table 1: $T$-test to compare means between Group (1) obese cases and Group (2) normal controls at base line.

\begin{tabular}{lcc}
\hline Variables & Mean $\pm \mathrm{SD}$ & P-value \\
\hline BMl $\left(\mathrm{kg} / \mathrm{m}^{2}\right)$ cases $(\mathrm{no} .=120)$ & $38.4 \pm 6.9$ & .000 \\
BMI $\left(\mathrm{kg} / \mathrm{m}^{2}\right)$ control (no.=30) & $24.1 \pm 1.2$ & .000 \\
\hline Vitamin D cases $(\mathrm{nmol} / \mathrm{L})$ & $47.6 \pm 7.7$ & \\
Vitamin D control (nmol/L) & $68.3 \pm 9.3$ & .000 \\
\hline Memory(OLT) cases & $41.5 \pm 4.1$ & .000 \\
Memory(OLT) control & $44.0 \pm 2.7$ & .000 \\
\hline Attention(DCT) cases & $82.8 \pm 12$ & \\
Attention(DCT) control & $72.3 \pm 7$ & \\
\hline FBG (mg/dl) cases & $119.5 \pm 40$ & \\
FBG (mg/dl) control & $82.1 \pm 6.7$ & \\
\hline P-value is significant at 0.000. &
\end{tabular}

P-value is significant at 0.000

Table 2 shows the changes occurred on the obese group after the 2 months on balanced low caloric diet comparing data before versus after the diet; significant decrease in the BMI and increase in mean VD level from $(47.6 \pm 7.7 \mathrm{nmol} / \mathrm{L})$ to $(53.5 \pm 8.4$ $\mathrm{nmol} / \mathrm{L}) \quad(P=0.000)$ accompanied by significant improvement in memory and attention scores $(P=$ $0.000)$ and decrease in FBG $(P=0.003)$ and improved insulin resistance $(P=0.029)$. Insignificant decrease in serum parathyroid hormone levels is seen.

Table 2: Paired $t$-test to compare means of Group (1) obese group before (B) and after (A) two months of low caloric diet.

\begin{tabular}{lcc}
\hline Variables & Mean \pm SD & P-value \\
\hline BMl $\left(\mathrm{kg} / \mathrm{m}^{2}\right)(B)$ & $38.4 \pm 6.9$ & .000 \\
BMl $\left(\mathrm{kg} / \mathrm{m}^{2}\right)(A)$ & $36.5 \pm 6.7$ & .000 \\
Vitamin D $(\mathrm{nmol} / \mathrm{L})(B)$ & $47.6 \pm 7.7$ & \\
Vitamin D $(\mathrm{nmol} / \mathrm{L})(A)$ & $53.5 \pm 8.4$ & .000 \\
OLT $(B)$ & $41.5 \pm 4.1$ & \\
OLT $(A)$ & $43.0 \pm 3.9$ & .000 \\
DCT $(B)$ & $82.8 \pm 12$ & \\
DCT $(A)$ & $78.9 \pm 11$ & .003 \\
F BG $(\mathrm{mg} / \mathrm{dll})(B)$ & $119.5 \pm 40$ & \\
FBG $(\mathrm{mg} / \mathrm{dll})(A)$ & $104 \pm 28.4$ & .029 \\
M.HOMA-IR $(B)$ & $1.62 \pm 9.3 \mathrm{E}-02$ & \\
M.HOMA-IR $(A)$ & $1.58 \pm 4.9 \mathrm{E}-02$ & .016 \\
C-Peptide $(\mathrm{ng} / \mathrm{ml})(B)$ & $2.6 \pm 1.1$ & \\
C-Peptide $(\mathrm{ng} / \mathrm{ml})(A)$ & $2.2 \pm 1.0$ & $\mathrm{NS}$ \\
PTH $(\mathrm{pg} / \mathrm{ml})(B)$ & $82.9 \pm 16.2$ & \\
PTH $(\mathrm{pg} / \mathrm{ml})(A)$ & $80.1 \pm 13$ & \\
\hline P-value is significant at $<0.05$ & &
\end{tabular}

Table 3 shows a significant positive correlation between VD serum level and cognitive functions [short-term memory $(P=0.039)$, and attention scores $(P=0.014)]$, while VD correlates negatively with PTH levels $(P=0.004)$.

Table 3: Correlation between different variables at the base line for Group (1) obese patients.

\begin{tabular}{lllll}
\hline Variables & Vitamin D & DCT & C-peptide & FBG \\
\hline BMI $\left(\mathrm{Kg} / \mathrm{m}^{2}\right)$ & & $\begin{array}{l}\mathrm{r}=0.487^{* *} \\
\mathrm{P}=.009\end{array}$ & $\begin{array}{l}\mathrm{r}=0.414^{*} \\
\mathrm{P}=.026\end{array}$ \\
\hline M.HOMA-IR & & $\mathrm{r}=0.382^{*}$ & $\mathrm{r}=0.863^{* \star}$ & $\mathrm{r}=.864^{* \star}$ \\
& & $\mathrm{P}=.041$ & $\mathrm{P}=.000$ & $\mathrm{P}=.000$ \\
\hline (Memory) OLT & $. \mathrm{r}=385^{*}$ & & $\mathrm{r}=0.374^{*}$ \\
& $\mathrm{P}=.0 .039$ & & $\mathrm{P}=.046$ \\
\hline (Attention) DCT & $\mathrm{r}=-0.450^{*}$ & & $\mathrm{r}=-0.446^{*}$ \\
& $\mathrm{P}=.014$ & & \\
\hline PTH (pg/ml) & $\mathrm{r}=-0.513^{* \star}$ & $\mathrm{r}=0.377^{*}$ & \\
\hline Numbers presented in this table are the value of $\mathrm{r}=$ correlation coefficient. *Correlation is
\end{tabular}

significant at the 0.05 level; $* *$ Correlation is significant at the 0.01 level.

\section{Discussion}

In our study the obese group showed vitamin $\mathrm{D}$ (VD) deficiency $(47.6 \pm 7.7 \mathrm{nmol} / \mathrm{L})$. Most studies define deficiency as less than $50 \mathrm{nmol} / \mathrm{L}$, the nonobese controls show a significantly higher VD (68.3 \pm 9.3) levels but is still considered below the adequate level ( $\geq 75 \mathrm{nmol} / \mathrm{L}$ ). It is important to mention this classification for VD Information from American Society of Bone and Mineral Research (ASBMR), 2006: Deficiency (seriously deficient) < $12 \mathrm{ng} / \mathrm{ml}$ resp. < $30 \mathrm{nmol} / \mathrm{l}$, Insufficiency (deficient) 12 - 30 $\mathrm{ng} / \mathrm{ml}$ resp. 30 - $75 \mathrm{nmol} / \mathrm{l}$, Sufficiency (adequately supplied) > $30 \mathrm{ng} / \mathrm{ml}$ resp. $>75 \mathrm{nmol} / \mathrm{l}$ (Society of Osteology SACHSEN E. V.

Several studies reported that low VD status is highly prevalent worldwide, and the major determinants are sun exposure and vitamin $D$ intake $[25,26]$. Another study reported that VD deficiency was highly prevalent among studied Saudi women who suffer from obesity, poor sunlight exposure and poor dietary VD supplementation [27]. In our study, the significant low level of VD compared to normal BMI controls can be explained by several mechanisms. A study suggested that VD deficiency increases appetite and decreases energy consumption leading to obesity. Another recent study suggested that the subcutaneous fat, which is known to store vitamin $D$, sequestered more of the cutaneous synthesized vitamin D3 in the obese than in the nonobese subjects because there was more fat available for this process. Because obese people have a larger body surface area, they present with a decreased release of endogenously produced VD in the circulation because of the vitamin's increased storage in subcutaneous fat. It is, however, unclear as to whether poor VD status is a consequence of obesity or is actively involved in its development [28-30].

Important study on VD deficiency and insufficiency on population in Eastern Africa, females reported lower serum concentration, with the younger 
population having lower serum concentrations than the elderly. Similarly central obesity was also highly prevalent in this population. The odds of being VD deficient were 3.3 times higher among individuals with elevated waist circumference than those with normal waist circumferences. Among the males, the odds of being Vitamin $D$ deficient and having an elevated waist circumference was 6.8 times higher than for males with normal waist circumferences. Their conclusion was living on or close to the equator and having overhead or near overhead sunshine throughout the year in and of itself is not a guarantee of adequate serum VD concentrations [11].

Another important finding in our study is that lower VD level is accompanied by lower cognitive functions scores. This finding has been mentioned in several recent studies relating cognitive impairment to low VD levels. A meta-analysis study compared mean cognitive functions scores between individuals with vitamin $\mathrm{D}<50$ and $\geq 50 \mathrm{nmol} / \mathrm{L}$. The vitamin $\mathrm{D}$ cut point of $50 \mathrm{nmol} / \mathrm{L}$ was selected, as it was the most common cut point reported in these studies, and is commonly used to define vitamin $\mathrm{D}$ deficiency. Eight cross-sectional and case-control studies, which included data from 2749 participants, contributed to this analysis. Taken together, these studies showed a higher average MMSE score in participants with higher VD concentrations [7, 31, 32]. The role of VD in skeletal health is well established, but more recent findings have also linked VD deficiency to a range of non-skeletal conditions such as cardiovascular disease, cancer, stroke and metabolic disorders including diabetes. Cognitive impairment and dementia must now be added to this list [28, 31]. VD receptors are widespread in brain tissue, and VD's biologically active form [1, $25(\mathrm{OH})$ 2D3] has shown neuroprotective effects including the clearance of amyloid plaques, a hallmark of Alzheimer's disease. Associations have been noted between low VD and Alzheimer's disease and dementia in both Europe and the US. Similarly, the risk of cognitive impairment was up to four times greater in the severely deficient elders $(\mathrm{VD}<25 \mathrm{nmol} / \mathrm{L})$ in comparison with individuals with adequate levels ( $\geq 75 \mathrm{nmol} / \mathrm{L}$ ), two large prospective studies recently indicated that low VD concentrations may increase the risk of cognitive decline. A study reported that hypovitaminosis $D$ is associated with global cognitive impairment in adults [1-4, 33].

Another 25 cross-sectional studies showed, a statistically significant worse outcome on one or more cognitive function tests or a higher frequency of dementia with lower VD levels or intake in 18 out of 25 $(72 \%)$ studies, whereas 7 (28\%) studies failed to show an association. Four out of $6(66.7 \%)$ prospective studies showed a higher risk of cognitive decline after a follow-up period of 4-7 years in participants with lower VD levels at baseline.

In conclusion, these results suggest that lower VD concentrations are associated with poorer cognitive function and a higher risk of $A D[1-3,6-8]$.

Another important finding in our study that fasting blood glucose is significantly higher in the obese group with lower vitamin D level. After 2 months of balanced low caloric diet a significant increase in mean VD is seen, accompanied by significant decrease in fasting blood sugar, improved insulin resistance and improved cognitive functions scores. So a link between VD levels and insulin resistance and serum blood glucose is seen adjoining the cognitive functions. We think that since subcutaneous fat, which is known to store VD, sequestered more of the cutaneous synthesized VD3 in the obese than in the non-obese subjects because there was more fat available for this process, then by losing fat and reduced BMI after the diet, VD is freed from the fat cells and escape to the blood. This in return improve the cognitive functions either directly through the neuroprotective action of VD previously mentioned or through the improved insulin resistance seen. Our results are supported by other studies that reported low VD levels were associated with increased insulin resistance and higher blood glucose in middle-aged and elderly Korean adults, especially among those who were overweight or obese. Korean girls with low VD levels could be at increased risk for metabolic disorders. The study supports the favorable effects of vitamin $D$ supplementation on reducing insulin resistance [34-36]. A lower VD level could be a risk factor for developing insulin resistance and type 2 diabetes in the obese population. A study suggested that glucose metabolism and body fat content depend on serum levels of VD. The study showed that low VD levels were associated with obesity, increased plasma glucose levels and decreased insulin sensitivity index $[36,37]$.

On the other hand a study reported that correcting low VD levels in obese adolescents improves insulin sensitivity. Adolescents who took 4000 IU of vitamin D3 daily had lower fasting insulin levels and insulin resistance than controls. Serum $25(\mathrm{OH}) \mathrm{D}$ had a negative relationship with fasting glucose and insulin resistance index [homeostasis model assessment-insulin resistance (HOMA-IR)] [38]. A previous study showed that intramuscular vitamin $D$ decreases insulin sensitivity in pre-diabetic patients. Serum $25(\mathrm{OH})$ vitamin D [25 $(\mathrm{OH}) \mathrm{D}]$ was found to be statistically associated with fasting insulin and HOMA-IR $[39,40]$ in all participants except for the fasting insulin in participants with BMls $<23 \mathrm{~kg} / \mathrm{m}^{2}$. A British study reported that obese individuals with insufficient vitamin $D$ had a 32-times higher risk for insulin resistance compared to those who are nonobese. To clarify this link a study reported that VD improves both $\beta$-cell function and the insulin sensitivity of target cells (liver, skeletal muscle, and adipose tissue) and protects $\beta$-cells from harmful immune attacks [41].

In our study a correlation is seen between 
vitamin $D$ serum level and cognitive functions (shortterm memory and attention scores). This can be explained that vitamin $D$ is important for fat metabolism, glucose metabolism and cognitive functions, which is translated as low vitamin D leads to obesity, insulin resistance and cognitive functions impairment. Previous studies reported an association between obesity and insulin resistance [38, 42]. The relation between insulin resistance and cognitive decline, especially memory impairment was mentioned in some studies [17]. Worldwide, approximately 347 million people are affected by diabetes, mainly type 2 diabetes. Recent epidemiological studies suggest that diabetic patients are at increased risk of dementia [18, 37]. The question whether the observed associations between these three ageing-related diseases are the result of shared risk factors or specific biological mechanisms, however, remains to be solved. Vitamin $D$ deficiency is one of the postulated links. Vitamin D administration could be a multi-target stabilizing treatment for cognitive impairment and dementia.

Lastly, our study showed that VD levels correlates negatively with parathyroid hormone (PTH) levels which is logical and has been previously reported. A study reported that serum VD and PTH levels correlate inversely. The VD levels at which PTH is maximally suppressed and below which $\mathrm{PTH}$ begins to rise (inflection point) has been used to define optimum VD levels. In overweight and obese children, the PTH axis is activated at much lower VD levels than in normal weight children. Increased PTH promotes calcium influx into adipocytes, where intracellular calcium enhances lipogenesis PTH excess may also promote weight gain. Therefore, the association between $\mathrm{V} D$ and obesity could change depending on serum PTH $[43,44]$.

In conclusion, our study shows VD deficiency among the obese females accompanied by cognitive impairment. After 2 months of balanced low caloric diet, VD levels increased, accompanied with improved cognitive functions and insulin resistance. We believe that low serum VD is a modifiable risk factor for obesity, insulin resistance and cognitive impairment in middle age Egyptian females.

\section{References}

1. Llewellyn DJ, Lang IA, Langa KM, Muniz-Terrera G. Vitamin D and risk of cognitive decline in elderly persons. Arch Intern Med. 2010; 170:1135-1141.

2. Llewellyn DJ, Lang IA, Langa KM, Melzer D. Vitamin D and cognitive impairment in the elderly US population. J Gerontol A Biol Sci Med Sci. 2010; 66: 59-65.

3. Maddock J1, Geoffroy MC, Power C, Hyppönen E .25Hydroxyvitamin $\mathrm{D}$ and cognitive performance in mid-life. $\mathrm{Br} \mathrm{J}$ Nutr. 2013; 18:1-11.

4. McCann JC, Ames BN.Is there convincing biological or behavioral evidence linking vitamin $D$ deficiency to brain dysfunction? FASEB J. 2008; 22(4):982-1001.
5. Eyles DW, Smith S, Kinobe R, Hewison M, McGrath JJ. Distribution of the vitamin $\mathrm{D}$ receptor and 1 alpha-hydroxylase in human brain. $\mathrm{J}$ Chem Neuroanat. 2005; 29:21-30.

6. Annweiler C, Allali G, Allain P, Bridenbaugh S, Schott AM Vitamin $D$ and cognitive performance in adults: a systematic review. Eur J Neurol. 2009; 16(10):1083-9.

7. Annweiler C, Montero-Odasso M, Llewellyn DJ, RichardDevantoy S. Meta-analysis of memory and executive dysfunctions in relation to vitamin D. J Alzheimers Dis. 2013; 37(1):147-71.

8. Annweiler C, Schott AM, Allali G, Bridenbaugh SA, Kressig RW.Association of vitamin $D$ deficiency with cognitive impairment in older women: cross-sectional study. Neurology. 2010; 74:27-32.

9. Gutiérrez-Medina S, Gavela-Pérez T, Domínguez-Garrido MN, Blanco-Rodríguez M, Garcés C, Rovira A, Soriano-Guillén L. [High prevalence of vitamin D deficiency among spanish obese children and adolescents.] An Pediatr (Barc). 2014; 80(4): 229-35.

10. Kelishadi R, Ardalan G, Motlagh ME, Shariatinejad $K$, Heshmat $R$. National report on the association of serum vitamin $D$ with cardiometabolic risk factors in the pediatric population of the Middle East and North Africa (MENA): the CASPIAN-III Study. Nutrition. 2014; 30(1):33-8.

11. Theuri G, Kiplamai F. Association between vitamin D levels and central adiposity in an eastern Africa outpatient clinical population. Dermatoendocrinol. 2013; 5(1):218-21.

12. ju-Seo JA, Eun CR, Cho H, Lee SK, Yoo HJ, Kim SG. Low vitamin $D$ status is associated with nonalcoholic Fatty liver disease independent of visceral obesity in Korean adults. PLoS One. 2013; 8(10):e75197.

13. Zhou JC1, Zhu YM, Guo P, Chen Z, Xie FZ, Liu XL, He S. Serum 25(OH)D and lipid levels in Chinese obese and normal weight males before and after oral vitamin D supplementation. Biomed Environ Sci. 2013; 26(10):801-7.

14. Elske M. Brouwer-Brolsma, Edith J. M. Feskens, Wilma T. Steegenga, Associations of 25-hydroxyvitamin D with fasting glucose, fasting insulin, dementia and depression in European elderly: the SENECA study .Eur J Nutr. 2013; 52(3): 917-925.

15. Sung CC, Liao MT, Lu KC, Wu CC. Role of vitamin D in insulin resistance. J Biomed Biotechnol. 2012; 2012: 634195.

16. Ou HY, Karnchanasorn R, Lee LZ, Chiu KC. Interaction of BMI with vitamin D and insulin sensitivity. Eur J Clin Invest. 2011; 41:1195-1201.

17. Gunstad J, Lhotsky A, Wendell CR, Ferrucci L, Zonderman $A B$. Longitudinal examination of obesity and cognitive function: results from the Baltimore longitudinal study of aging. Neuroepidemiology. 2010; 34(4):222-9

18. Xu WL, Atti AR, Gatz M, Pedersen NL, Johansson B, Fratiglioni L. Midlife overweight and obesity increase late-life dementia risk: A population-based twin study. Neurology. $2011 ; 76$.

19. Gibson A J and Kindrick DC. The Kendrick battery for the detection of dementia in the elderly. NFER publishing company, 1977.

20. Barham D., Trinder P. An improved color reagent for determination of blood glucose by oxidase system. Analyst. 1972; 97:142-145

21. Field J.B. Hypoglycemia: Definition, clinical presentations, classification and laboratory tests. Endocrinol Metab Clin. North Am. 1989; 18:27-43.

22. Li X, Zhou ZG, Qi HY et al. Replacement of insulin by fasting C-peptide in modified homeostasis model assessment to evaluateinsulin resistance and islet beta cell function. Zhonghua Yi Xue Yi Chuan Xue ZaZhi (Chinese). 2004; 29(4):419-423. 
23. Wielders JP, Wijnberg FA. Preanalytical stability of $25(\mathrm{OH})$ vitamin D3 in human blood or serum at room temperature: solid as a rock. Clin Chem. 2009; 55(8):1584-1585.

24. Bouillon R, Coopmans W, De Groote DEH, Radoux D, Eliard $\mathrm{PH}$. Immunoradiometric assay of Parathyrin with polyclonal andmonoclonal region specific antibodies. Clin Chem. 1990; 36(2):271-276.

25. Suárez-Martínez EB, Pérez CM, Cruz SK, Khorsandi S, Chardón C, Ferder L. Importance of vitamin D and vitamin D levels status in Puerto Ricans. J Health Care Poor Underserved. 2013; 24(4): 38-47.

26. Choi HS, Oh HJ, Choi H, Choi WH, Kim JG, Kim KM, Kim KJ, Rhee Y, Lim SK. Vitamin D insufficiency in Korea: a greate threat to younger generation: the Korea National Health and Nutrition Examination Survey (KNHANES) 2008. J Clin Endocrinol Metab. 2011; 96:643-651.

27. Ardawi MS, Qari MH, Rouzi AA, Maimani AA, Raddadi RM Vitamin $D$ status in relation to obesity, bone mineral density, bone turnover markers and vitamin $D$ receptor genotypes in healthy Saudi pre- and postmenopausal women. Osteoporos Int. $2011 ; 22(2): 463-75$.

28. Kang JH, Kim SS, Moon SS, Kim WJ, Bae MJ, Choi BG, Jeon YK, Kim BH, Kim YK, Kim IJ. Adiposity in the Relationship between Serum Vitamin D Level and Insulin Resistance in Middle-Aged and Elderly Korean Adults: The Korea National Health and Nutrition Examination Survey 2008. Endocrinol Metab (Seoul). 2013;28(2):96-102.

29. Wortsman J, Matsuoka LY, Chen TC, Lu Z, Holick MF. Decreased bioavailability of vitamin $\mathrm{D}$ in obesity. Am J Clin Nutr. 2000; 72:690-693.

30. Sergeev IN, Song Q. High vitamin D and calcium intakes reduce diet-induced obesity in mice by increasing adipose tissue apoptosis. Mol Nutr Food Res. 2014 Jan 22.

31. Brouwer-Brolsma EM, van de Rest O, Tieland M .Serum 25hydroxyvitamin $d$ is associated with cognitive executive function in dutch prefrail and frail elderly: a cross-sectional study exploring the associations of 25-hydroxyvitamin $d$ with glucose metabolism, cognitive performance and depression. J Am Med Dir Assoc. 2013; 14(11):852.e9-17.

32. Lee DM, Tajar A, Ulubaev A, Pendleton N, O'Neill TW, O'Connor DB, Bartfai G. Association between 25hydroxyvitamin $D$ levels and cognitive performance in middleaged and older European men. J Neurol Neurosurg Psychiatr. 2009; 80:722-729.

33. Dean AJ, Bellgrove MA, Hall T, Phan WM, Eyles DW, Kvaskoff D, McGrath JJ. Effects of vitamin D supplementation on cognitive and emotional functioning in young adults-a randomised controlled trial. PLoS One. 2011; 6 (11): e25966.

34. Belenchia AM, Tosh AK, Hillman LS, Peterson CA. Correcting vitamin $D$ insufficiency improves insulin sensitivity in obese adolescents: a randomized controlled trial. Am J Clin Nutr. 2013; 97: 774-781.

35. Kang JH, Kim SS, Moon SS, Kim WJ, Bae MJ, Choi BG.Adiposity in the Relationship between Serum Vitamin D Level and Insulin Resistance in Middle-Aged and Elderly Korean Adults: The Korea National Health and Nutrition Examination Survey 2008. Endocrinol Metab (Seoul). 2013; 28(2):96-102.

36. Kelly A, Brooks LJ, Dougherty S, Carlow DC, Zemel BS. A cross-sectional study of vitamin $D$ and insulin resistance in children. Arch Dis Child. 2011; 96: 447-452.

37. Danaei G, Finucane MM, Lu Y, Singh GM, Cowan MJ.National, regional, and global trends in fasting plasma glucose and diabetes prevalence since 1980: systematic analysis of health examination surveys and epidemiological studies with 370 country-years and 2.7 million participants. Lancet. 2011; 378:31-40.
38. Joffe A. Correcting Low Vitamin D Levels in Obese Adolescents Improves Insulin Sensitivity. Journal Watch Pediatrics and Adolescent Medicine. Am J Clin Nutr. 2013;39.

39. Kabadi SM, Lee BK, Liu L. Joint effects of obesity and vitamin $D$ insufficiency on insulin resistance and type 2 diabetes: results from the NHANES 2001-2006. Diabetes Care. 2012; 35:2048-2054.

40. Matthews DR, Hosker JP, Rudenski AS, Naylor BA, Treacher DF, Turner RC. Homeostasis model assessment: insulin resistance and beta-cell function from fasting plasma glucose and insulin concentrations in man. Diabetologia. 1985;28: 412-419.

41. Bland R, Markovic D, Hills CE, Hughes SV, Chan SL, Squires $\mathrm{PE}$, Hewison M. Expression of 25-hydroxyvitamin D3-1alphahydroxylase in pancreatic islets. J Steroid Biochem Mol Biol. 2004; 89-90:121-125.

42. Danziger J1, Biggs ML, Niemi M, Ix JH, Kizer JR, Djoussé L. Circulating 25-hydroxyvitamin $\mathrm{D}$ is associated with insulin resistance cross-sectionally but not longitudinally in older adults: The Cardiovascular Health Study. Metabolism. 2013; 62(12):1788-94.

43. Amini Z1, Bryant S, Smith C, Singh R, Kumar S. Is the serum vitamin D-parathyroid hormone relationship influenced by obesity in children? Horm Res Paediatr. 2013; 80(4):252-6.

44. Grethen E, McClintock R, Gupta CE, Jones R, Cacucci BM. Vitamin D and hyperparathyroidism in obesity. J Clin Endocrinol Metab. 2011; 96:1320-1326. 